\title{
SEISMIC PERFORMANCE ASSESSMENT OF REINFORCED CONCRETE SETBACK BUILDINGS
}

\author{
Shibajee Sutar ${ }^{1}$, Lipika Halder ${ }^{2} *$ \\ ${ }^{1}$ Graduate Student, Department of Civil Engineering, National Institute of Technology Agartala, India, 799046, \\ Email: shibajeesutar@gmail.com \\ ${ }^{2}$ Assistant Professor, Department of Civil Engineering, National Institute of Technology Agartala, India, 799046, \\ Email: erlhalder@yahoo.co.in
}

\begin{abstract}
Construction of irregular buildings both in plan and elevation is very common due to space, architectural and functional constraints. However, past earthquakes (the 2001 Bhuj Earthquake, 2011 Sikkim earthquake etc.) demonstrated that irregular buildings are more vulnerable and experienced more damage during seismic excitation. Therefore, before going to design setback buildings, it is very much essential to understand the seismic performance of these buildings. In this paper, an analytical study has been carried out to understand the differences in various responses of setback buildings as compared to regular buildings. To fulfill the objectives reinforced concrete buildings with different storey level like, 3, 5, and 10 storied buildings are considered and for each building seven different setback configurations have been introduced. Accordingly, total 24 numbers, $3 D$ reinforced concrete building models have been designed as per Indian code IS 1893:2002, IS 456:2000 and analyzed using SAP 2000 v (17.2.0). Response spectrum analysis is performed on all the buildings and variation in response quantities such as shear forces, bending moments etc. in different structural element have been assessed by comparing between the regular and setback buildings. This study may help the practicing engineers to improve the understanding about seismic vulnerability of setback buildings.
\end{abstract}

Keywords: Irregular, time period, RCC, Setback, Response spectrum

\section{INTRODUCTION}

Due to space constrains, construction of irregular multistoried reinforced concrete frames buildings are very common in urban India. According to major seismic codes, the irregular structures are classified as plan irregular and vertical irregular structures. The irregularity in the building structures may be due to irregular distributions in their mass, strength and stiffness along the height of building. Among all, a very common type of irregularity in structure arises from abrupt change in lateral dimension of the structure at specific level which is known as setback buildings. These irregular structures undergo yielding and ultimately failure starts at the point of weakness when these are subjected to ground motion.

Irregular configuration in plan and elevation are usually recognized as one of the main causes of failure during past earthquake ${ }^{[1,2]}$. Focusing on building with setbacks, damages observed after earthquake indicates an inferior performance of this type of structure. Several analytical studies investigate behavioral aspects of setback structures and limitation of seismic code provisions for such class of building. It has been found in the literature that a discontinuity in frame markedly increase the ductility demand twice as high as those of regular buildings ${ }^{[3]}$ and the damage is concentrated in the setback portion due to high rotational ductility ${ }^{[4]}$. The earthquake response of different storey frame structures with varying mass, stiffness and strength distribution was evaluated considering different codes ${ }^{[5-7]}$, and it was concluded that the combined effect of stiffness-and-strength irregularity is the largest than the others. Also the roof displacement is not affected by the vertical irregularity and $\mathrm{UBC}^{[12]}$ makes restriction on the applicability of simplified method for structures with consistent irregularities. To review the performance of irregular building, some experimental studies on symmetrical and unsymmetrical arrangements of setbacks were conducted previously and the studies show that lateral deformation at the lower floors of the of the frames reduced considerably ${ }^{[8]}$. The setback fames experienced the largest acceleration amplification factors. Maximum accelerations at the top of the setback frames were approximately twice those measured at the top of the uniform frames ${ }^{[9]}$. Nevertheless, from the past studies it was observed that the setback frame structures show an inferior performance on earthquakes.

Study of all these literatures reveal that the behaviors of setback building structure are very uncertain; and in most of the studies two dimensional frame models were considered which an idealization that rarely occurs in reality. In this paper, an attempt has been made to understand the dynamic response of different setback buildings of varying height. Response spectrum analysis is performed on the regular and setback buildings and variation in response quantities such as shear forces, bending moments etc. in different structural element have been assessed by comparing between the regular and setback buildings. This study may help the practicing engineers to improve the understanding about seismic vulnerability of setback buildings. 


\section{GEOMETRICAL CONFIGURATION OF THE BUILDING CONSIDERED}

The present study is based on three dimensional regular $\mathrm{RC}$ buildings and an extensive set of setback building frame models with varying degree of irregularity or amount of setback. Three different height categories are considered as 3,5 , and 10 storey with a uniform storey height of 3 meter and with a plinth of 1.5 meter. There are altogether eight different building geometries in each category, one regular and seven irregular setback buildings. The regular frame is named as 3-R where 3 represent the number of storey and $\mathrm{R}$ represent regular. In setback building, the nomenclatures are 3-S-1 to 3-S-7, where 3 represent number of storey and S-1 shows the setback case. Total 24 reinforced concrete moment resisting frames, that are shown in Fig. 1 were designed according to the requirement of Indian Standard code IS 1893:2002 $2^{[10]}$ and IS 456:2000 $0^{[11]}$. In all the frames, the floor diaphragms are considered as rigid in their plane and each nodal point in the frame has six degrees of freedom, three translations and three rotations. The

where, $\quad \frac{S_{a}}{g}= \begin{cases}1+15 \mathrm{~T} ; \text { when } & 0.00 \leq \mathrm{T} \leq 0.10 . \\ 2.50 ; & 0.10 \leq \mathrm{T} \leq 0.55 . \\ 1.36 / \mathrm{T} ; & 0.55 \leq \mathrm{T} \leq 4.00\end{cases}$

\section{ASSESSMENT OF SEISMIC PERFORMANCE}

\subsection{Global Performance of the Structure:}

All the twenty four buildings have been analyzed by applying seismic force both in $\mathrm{X}$ and $\mathrm{Y}$ direction independently and subsequent results are presented. The dynamic response of all the building frames in terms of fundamental time period is presented in Table 2. It is observed that the value of fundamental time period obtained by dynamic analysis is substantially higher than the values estimated by empirical equation given in 1893:2002 (Part 1) ${ }^{[11]}$. The value of fundamental time period varies in a range of 0.565 to $0.978,0.724$ to 1.07 and 1.122 to 1.525 for 3,5 and 10 storey building respectively.

The performance of the structure in terms of shear force and bending moment was also assessed. Shear force and bending moment of all the buildings have been normalized with respect to the regular building which is summarized in Fig. 2(a), (b), and (c) and Fig. 3(a), (b), and (c) respectively in X and $\mathrm{Y}$ direction for 3, 5 and 10 storey buildings.

In Fig. 2, storey-wise variation in maximum shear force is shown for all the building frames. The results have been plotted as normalized shear force versus number of storey. The normalized shear forces are given at the base, $1^{\text {st }}$ storey $2^{\text {nd }}$ storey, $3^{\text {rd }}$ storey and so on up to roof level. It is observed that there is an abrupt variation in shear force in column of setback building. It is also noted that the top storey column of setback case 7 (3-S-7, 5-S-7 and 10-S-7) compressive strength of concrete is taken as $25 \mathrm{~N} / \mathrm{mm}^{2}$ and steel has yield strength of $415 \mathrm{~N} / \mathrm{mm}^{2}$. All the frame structures are modeled and analyzed using SAP 2000 (17.2.0) package. The size of the beam and column and the reinforcement detailed is given in Table 1.

\section{METHOD OF ANALYSIS}

The seismic analysis of all the building frames are carried out by response spectrum analysis (RSA) by using IS 1893:2002 (Part 1) ${ }^{[11]}$. The frame structures are considered to be situated in seismic zone $\mathrm{V}$ and accordingly $\mathrm{Z}$ is taken as $.36 \mathrm{~g}$ and medium type of soil is considered. The frame structure is considered as residential building and hence the importance factor is taken as 1 with 5\% damping. The buildings are considered as ordinary moment resistant frame (OMRF) buildings and so, the response reduction factor is taken as 3. For all the frame structures the modal responses were combined using SRSS method. The following design spectrum was utilized in response spectrum analysis.

Spectral Acceleration Coefficient, and $\mathrm{T}=$ Time Period experiences $33-53 \%$ increase in shear force both in $\mathrm{X}$ and $\mathrm{Y}$ directions than the regular building frame. Also, the shear force on the top storey column of setback case 2 (3-S-2, 5-S2 and10-S-2) is abruptly increased by $33-50 \%$ in $\mathrm{X}$ direction rather than in $\mathrm{Y}$.

In Fig. 3, storey-wise variation in maximum bending moment is shown for all the building frames. The results have plotted as normalized bending moment versus storey. The normalized shear forces are given at the base, $1^{\text {st }}$ storey $2^{\text {nd }}$ storey, $3^{\text {rd }}$ storey and so on up to roof level. It is observed that there is an abrupt variation in bending moment in setback building frames column. It is also noted that, in comparison to all the frame structures, the top storey column of setback case 7 (3-S-7, 5-S-7 and 10-S-7) experiences $32-50 \%$ increase in bending moment both in $\mathrm{X}$ and $\mathrm{Y}$ directions than the regular building frame. Also, the bending moment on the top storey column of setback case 2 (3-S-2, 5-S-2 and10-S-2) is abruptly increased by $49-87 \%$ in $\mathrm{X}$ direction rather than in $\mathrm{Y}$.

\subsection{Local Performance of the Structure:}

Figs. 4- 6 portray the percentage increase in shear force and bending moment at different column of 3,5 and 10 storey buildings respectively. Columns of regular building frame are compared with irregular setback frames with respective colors.

From Fig. 4 it could be inferred that Setback case 3-S-2 and $3-\mathrm{S}-7$ are more vulnerable as the percentage increase in 
shear force and bending moment is varying from $65-76 \%$ and $50-63 \%$ respectively. Similar trend are also observed in case of 5 and 10 storey buildings particularly in Setback case 5-S-2, 5-S-7, 10-S-2 and 10-S-7, which can also be shown from Figs.5-6. Interestingly in the setback case 3-S3 , it is found that shear force and bending moment are decreased for about $3 \%$ and $11 \%$ respectively in $\mathrm{X}$ direction, However, when the same was analyzed in $\mathrm{Y}$ direction, structure shows vulnerability again with the increase of shear force and bending moment over $21 \%$ and $20 \%$ respectively. $\%$ and 10 storey buildings also show the same trend in the Setback case 5-S-1 and 10-S-1.

\section{CONCLUSIONS}

Based on the dynamic analysis of low, medium and high rise regular and setback buildings, the following conclusion can be drawn:

a) The fundamental time period decreases with the introduction of setback to the building frames, which results in the increase of the spectral acceleration coefficient and ultimately increases the base shear. Since, the base shear is increased; the vulnerability of setback building frames is more than regular building during an earthquake.

b) For all building frames, there is an abrupt variation in shear force and bending moment at the level where setback is introduced.

c) The top story columns of setback case 2 and setback case 7 building experiences large amount of shear force and bending moment due to setback.

d) The S-2 and S-7 building are found to be most vulnerable than the other, since the columns of this frame experience about $70 \%$ and $60 \%$ more shear force and bending moment respectively.

\section{NOTATION}

a) $\mathrm{OMRF}=$ Ordinary Moment Resisting Frame.

b) $\mathrm{R}=$ Regular Building Frame.

c) $\mathrm{RSA}=$ Response Spectrum Analysis.

d) SRSS = Square Root of the Sum of the Square.

e) $\mathrm{S}=$ Setback Building Frame.

f) $\mathrm{T}=$ Time Period.

g) $\frac{S_{a}}{g}=$ Spectral Acceleration Coefficient.

\section{REFERENCES}

[1] Kaushik, H.B., Dasgupta, k. "Assessment of Seismic Vulnerability of Structures in Sikkim (India) based on Damage Observation during Two Recent Earthquakes". Journal of Performance of Constructed Facilities. ASCE. 1973-5509.0000380, 2012.

[2] Jain , S.K. ,Mitra , K. , Kumar, M. , Shah , M. "A Proposed Raid Visual Screening Procedure for Seismic Evaluation of RC- Frame Buildings in India". Earthquake Spectra. Earthquake Engineering Research Institute. V 26. N0. 3, 2010, pp. 709-729.

[3] Costa, Anibal G., Carlos S. Oliveira and Ricardo T. Duarte,. "Influence of Vertical Irregularities on Seismic Response of Buildings." proceedings of ninth world conference on earthquake engineering 5, 1988.

[4] Shahrooz, B.M. and Moehle, J.P. "Seismic Response and Design of Setback Buildings", Journal of Structural Engineering, ASCE, Vol. 116, No. 5, 1990 pp. 1423-1439.

[5] Valmundsson, E.V. and Nau, J.M. "Seismic Response of Building Frames with Vertical Structural Irregularities", Journal of Structural Engineering, ASCE, Vol. 123, No. 1, 1997, pp. 30-41.

[6] Al-Ali, A.A.K. and Krawinkler, H. "Effects of Vertical Irregularities on Seismic Behavior of Building Structures", Report No. 130, The John A. Blume Earthquake Engineering Center, Department of Civil and Environmental Engineering, Stanford University, and Stanford, U.S.A, 1998.

[7] Das, S. and Nau, J.M. "Seismic Design Aspects of Vertically Irregular Reinforced Concrete Buildings", Earthquake Spectra, Vol. 19, No. 3, 2003, pp. 455-477.

[8] Wood, S.L. "Seismic Response of R/C Frames with Irregular Profiles", Journal of Structural Engineering, ASCE, Vol. 118, No. 2, 1992, pp. 545-566

[9] Lee, H.S., Ko, D.W. "Seismic response of high-rise $\mathrm{RC}$ bearing-wall structures with irregularities at bottom stories". Proceedings of the 13th World Conference on Earthquake Engineering, Vancouver, Canada, 2004.

[10] BIS (2002). "IS 1893 (Part 1): 2002-Indian Standard Criteria for Earthquake Resistant Design of Structures, Part 1: General Provisions and Buildings (Fifth Revision)", Bureau of Indian Standards, New Delhi.

[11] BIS (2000). "IS 456: 2000-Indian Standard Plain and Reinforced Concrete-Code of Practice (Fourth Revision)", Bureau of Indian Standards, New Delhi.

[12] Uniform Building Code _UBC_. _1997_. "International conference of building officials." UBC 97, Vol. 2, Whittier, Calif. 
Table 1: Beam and Column Details

\begin{tabular}{|c|c|c|c|c|c|}
\hline Frames & Members & Floors & Width(mm) & $\operatorname{Depth}(\mathrm{mm})$ & Reinforcement \\
\hline \multirow{4}{*}{3 storey } & Column & 1 & 350 & 350 & $\# 12$ - 20d \\
\hline & Column & 2 to 3 & 350 & 350 & $\# 10-20 d$ \\
\hline & Beam & 1 to 2 & 300 & 300 & $\# 3$ - 25d top, \#3 - 20d bottom \\
\hline & Beam & 3 & 250 & 250 & $\# 4$ - 16d top, \#3 - 16d bottom \\
\hline \multirow{7}{*}{5 storey } & Column & 1 & 450 & 450 & $\# 14-20 \mathrm{~d}$ \\
\hline & Column & 2 & 450 & 450 & $\# 12-20 d$ \\
\hline & Column & 3 & 400 & 400 & $\# 12-20 d$ \\
\hline & Column & 4 & 400 & 400 & $\# 10$ - 20d \\
\hline & Column & 5 & 350 & 350 & $\# 08-20 \mathrm{~d}$ \\
\hline & Beam & 1 to 4 & 400 & 400 & $\# 4$-25d top, \#4 - 20d bottom \\
\hline & Beam & 5 & 350 & 350 & $\# 4$ - 16d top, \#3 - 16d bottom \\
\hline \multirow{8}{*}{10 storey } & Column & 1 & 600 & 600 & $\# 12-25 \mathrm{~d}$ \\
\hline & Column & 2 to 3 & 550 & 550 & $\# 12-25 d$ \\
\hline & Column & 4 to 6 & 500 & 500 & $\# 12-25 d$ \\
\hline & Column & 7 to 8 & 450 & 450 & $\# 14-20 d$ \\
\hline & Column & 9 & 450 & 450 & $\# 12-20 d$ \\
\hline & Column & 10 & 450 & 450 & $\# 10-20 \mathrm{~d}$ \\
\hline & Beam & 1 to 9 & 500 & 500 & $\# 6$ - 25d top, \#3 - 25d bottom \\
\hline & Beam & 10 & 400 & 400 & $\# 4$ - 16d top, \#3 - 16d bottom \\
\hline
\end{tabular}

Table 2: Dynamic response of all the frames in terms of fundamental time period

\begin{tabular}{|c|c|c|c|}
\hline \multirow{2}{*}{\multicolumn{2}{|c|}{ Type of Structure }} & \multicolumn{2}{|c|}{ Time Period in sec } \\
\hline & & \multirow{2}{*}{$\begin{array}{c}\text { From IS } 1893 \\
0.437\end{array}$} & \multirow{2}{*}{$\begin{array}{c}\text { From RSA } \\
0.978\end{array}$} \\
\hline \multirow{8}{*}{3 Storey } & $3-\mathrm{R}$ & & \\
\hline & $3-S-1$ & 0.437 & 0.868 \\
\hline & $3-S-2$ & 0.437 & 0.704 \\
\hline & $3-S-3$ & 0.437 & 0.726 \\
\hline & $3-S-4$ & 0.437 & 0.69 \\
\hline & $3-S-5$ & 0.437 & 0.737 \\
\hline & $3-S-6$ & 0.437 & 0.711 \\
\hline & $3-S-7$ & 0.437 & 0.565 \\
\hline \multirow{8}{*}{5 Storey } & $5-\mathrm{R}$ & 0.614 & 1.07 \\
\hline & $5-S-1$ & 0.614 & 0.8963 \\
\hline & $5-S-2$ & 0.614 & 0.945 \\
\hline & $5-S-3$ & 0.614 & 0.864 \\
\hline & $5-\mathrm{S}-4$ & 0.614 & 0.897 \\
\hline & $5-S-5$ & 0.614 & 1.0281 \\
\hline & $5-S-6$ & 0.614 & 0.903 \\
\hline & $5-S-7$ & 0.614 & 0.724 \\
\hline \multirow{8}{*}{10 Storey } & $10-\mathrm{R}$ & 0.997 & 1.525 \\
\hline & 10-R-1 & 0.997 & 1.343 \\
\hline & 10-R-2 & 0.997 & 1.366 \\
\hline & $10-\mathrm{R}-3$ & 0.997 & 1.32 \\
\hline & 10-R-4 & 0.997 & 1.294 \\
\hline & $10-\mathrm{R}-5$ & 0.997 & 1.454 \\
\hline & 10-R-6 & 0.997 & 1.296 \\
\hline & 10-R-7 & 0.997 & 1.122 \\
\hline
\end{tabular}




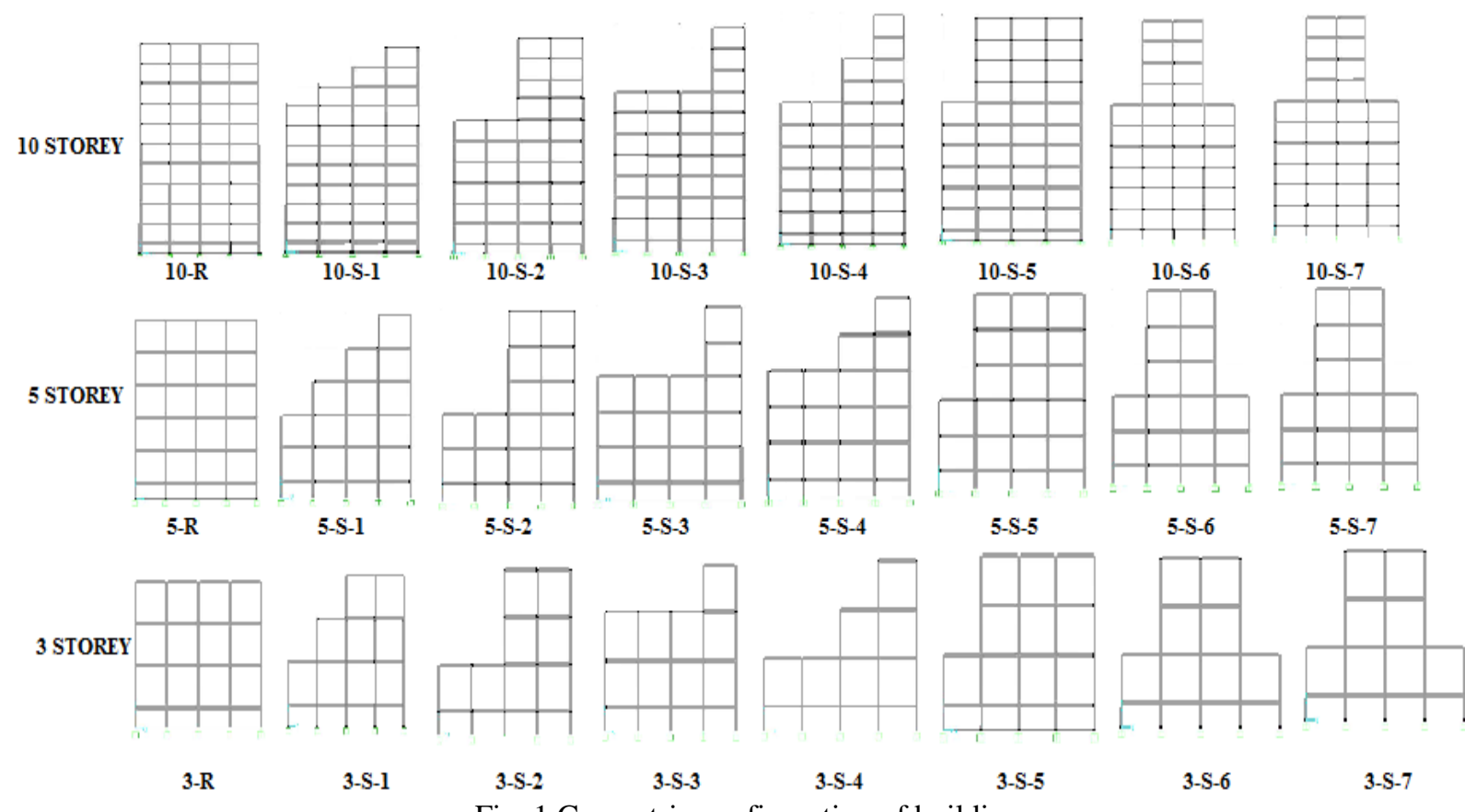

Fig. 1 Geometric configuration of building
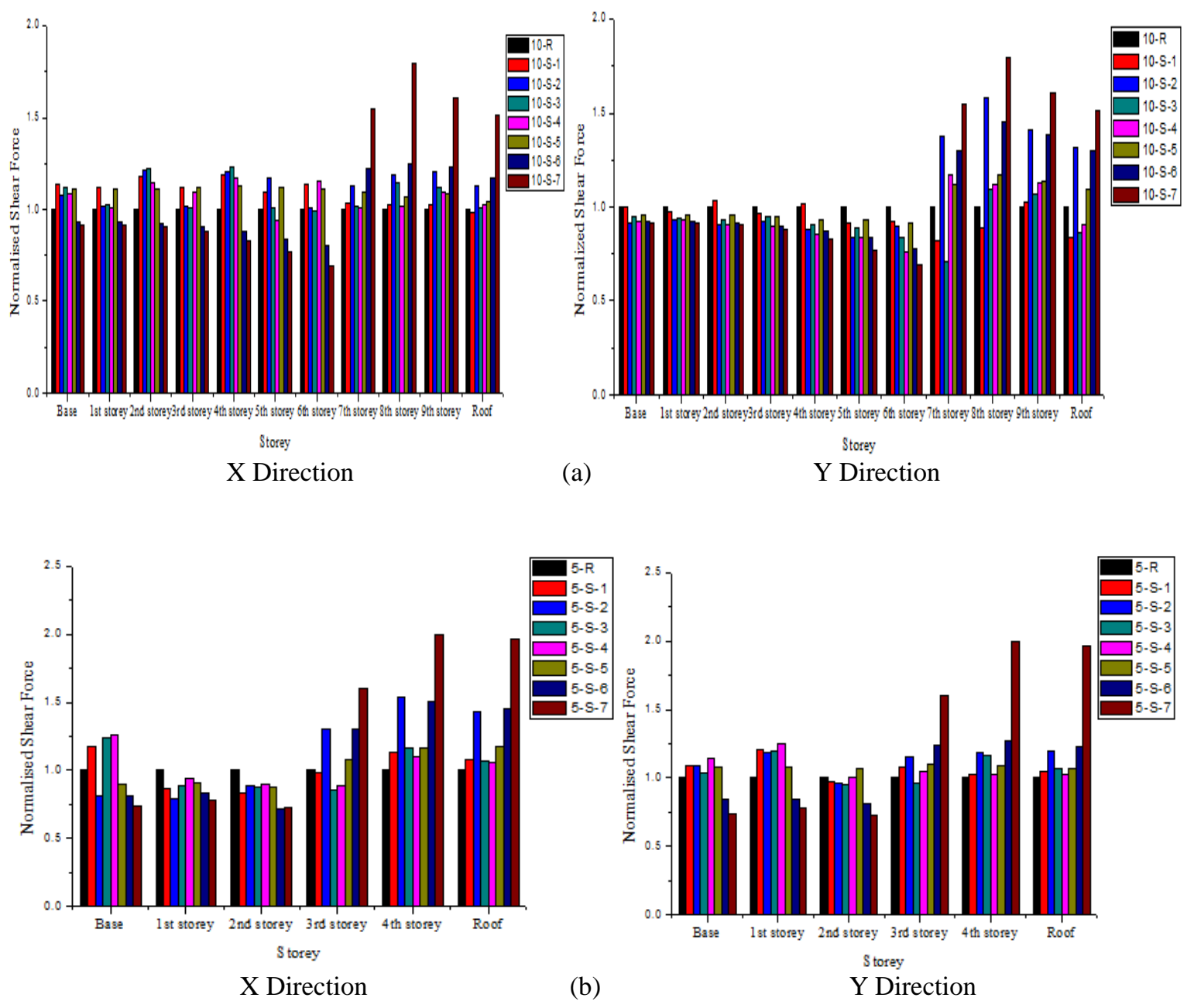

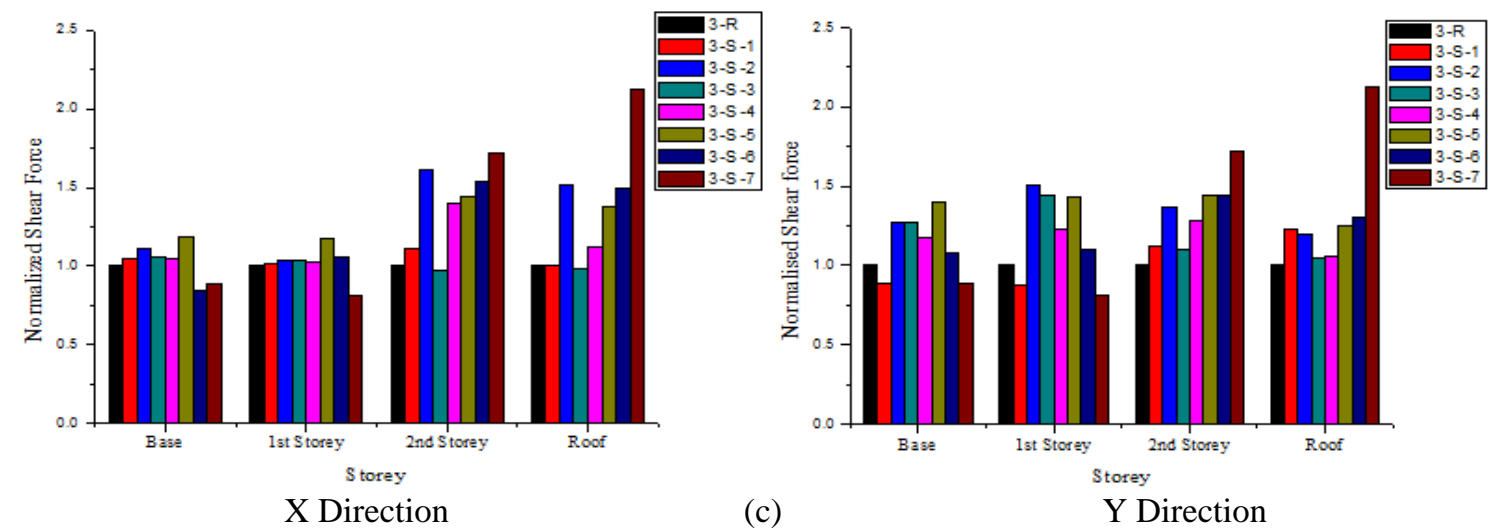

Fig. 2 Variation of the maximum shear force obtained from setback building to that obtained from regular building at different storey level for (a) 3 storied building; (b) 5 storied building; and (c) 10 storied building.
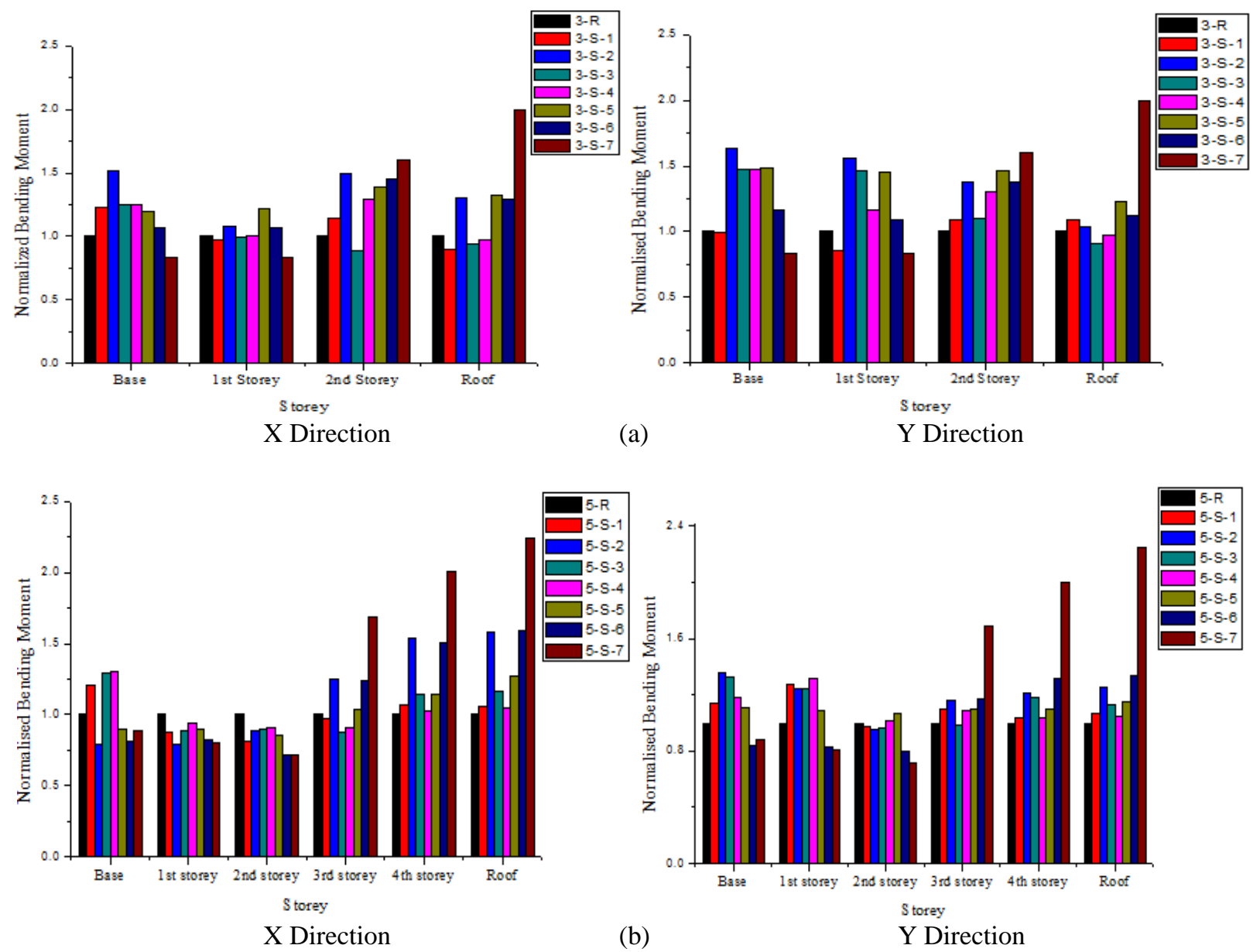

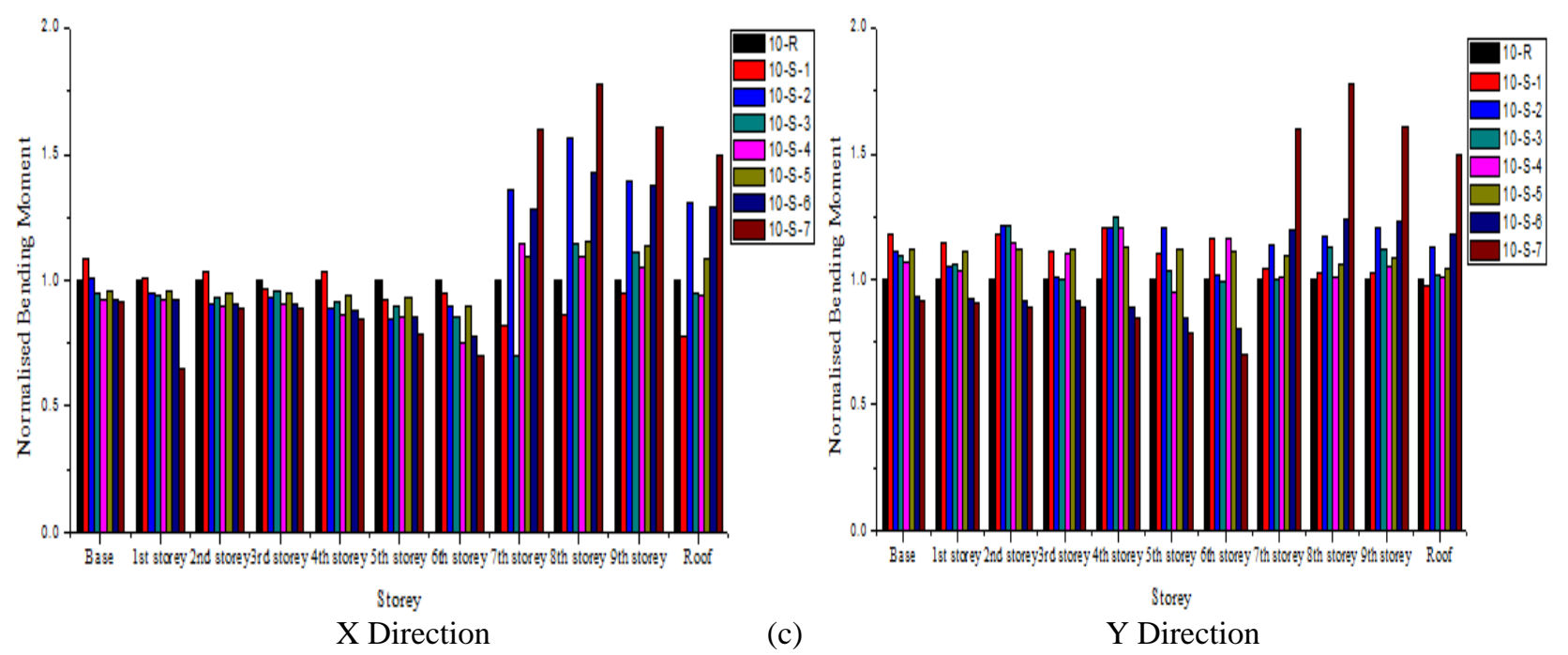

Fig. 3 Variation of the maximum bending moment obtained from setback building to that obtained from regular building at different storey level for (a) 3 storied building; (b) 5 storied building; and (c) 10 storied building.

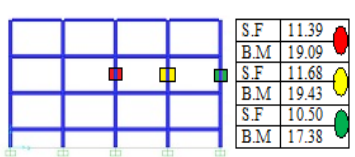

3-R

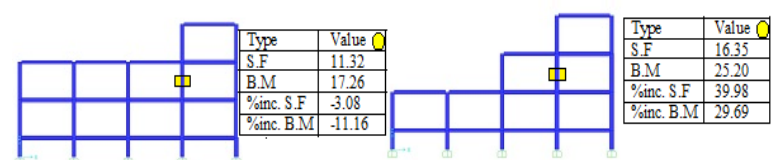

3-S-3

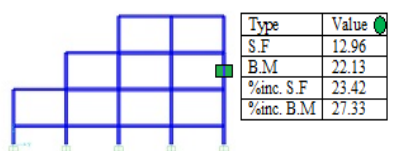

3-S-1

3-S-4

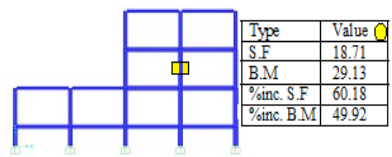

3-S-2

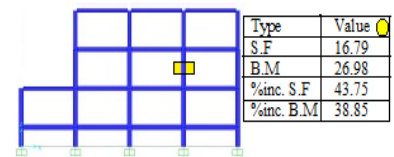

3-S-5

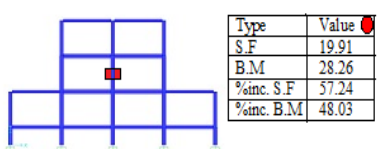

3-S-6

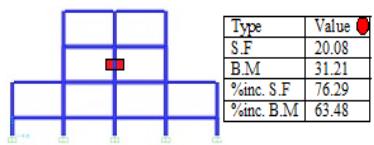

3-S-7

X Direction

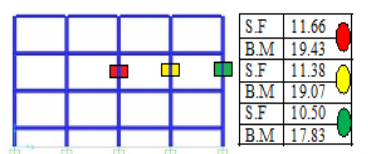

3-R

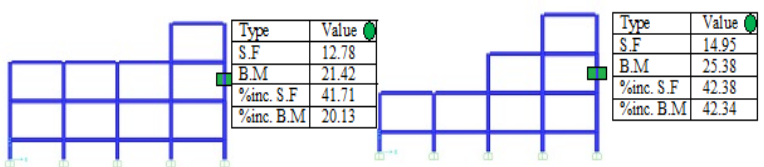

3-S-3

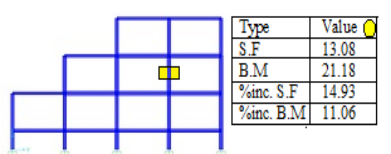

3-S-1

3-S-4

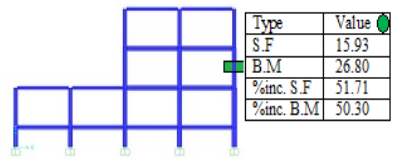

3-S-2

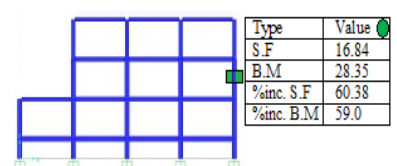

3-S-5

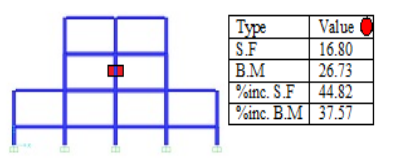

3-S-6

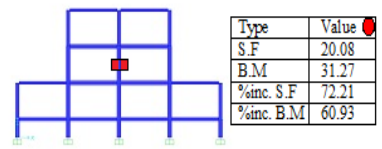

3-S-7

Y Direction

Fig. 4 Variation in shear force and bending moment at different columns obtain from response spectrum analysis of 3 storey regular building to that of setback building. 


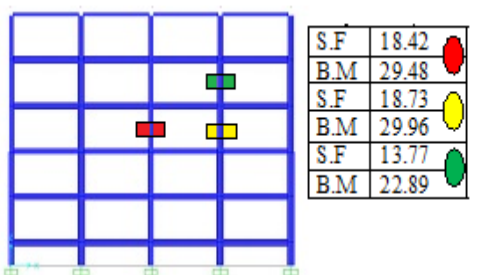

5-R

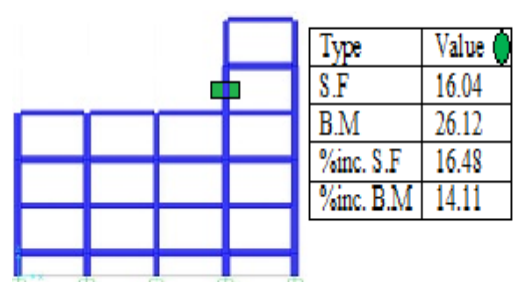

5-S-3

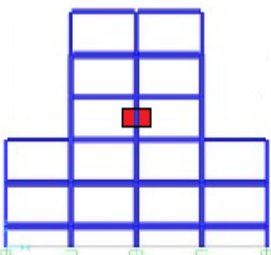

5-S-6

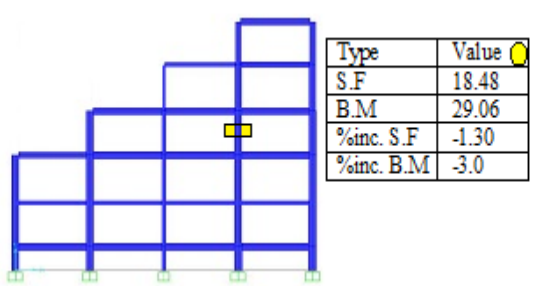

5-S-1

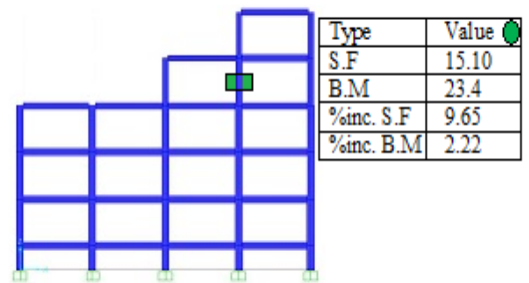

5-S-4

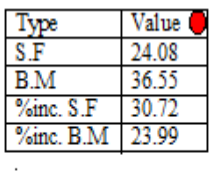

X Direction

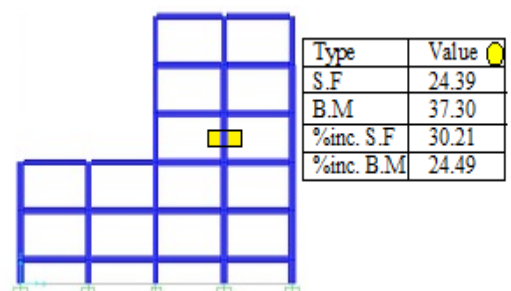

5-S-2

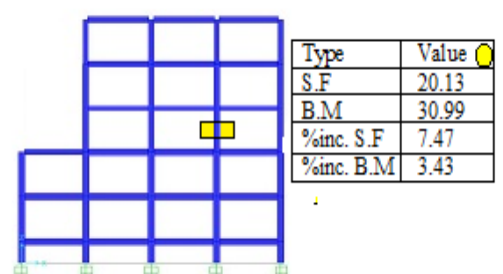

5-S-5

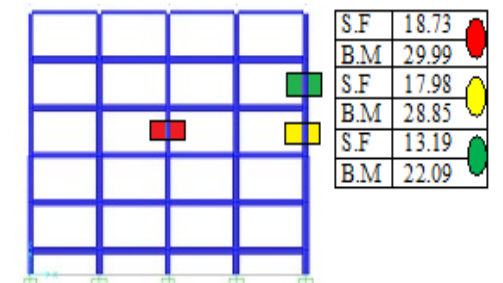

5-R

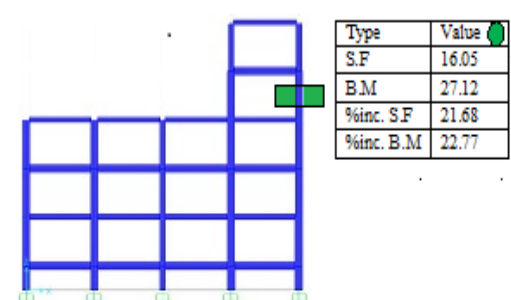

5-S-3

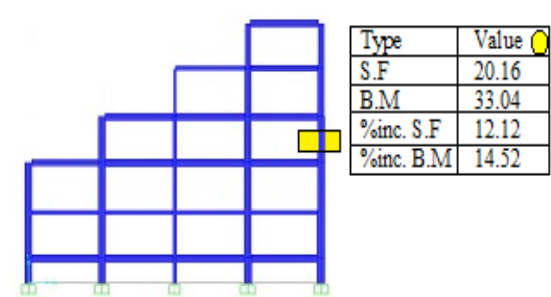

5-S-1

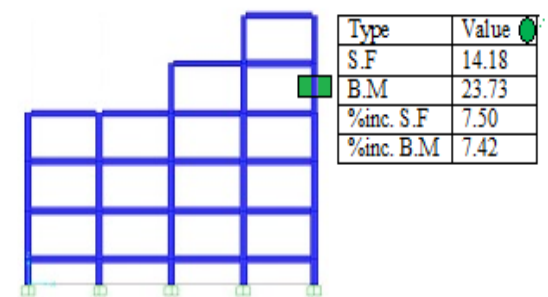

5-S-4

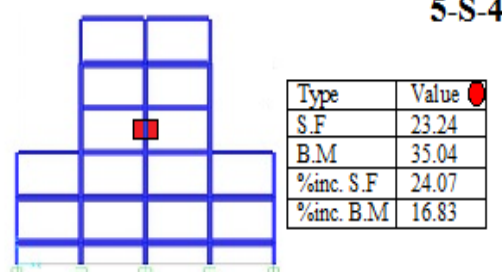

5-S-6

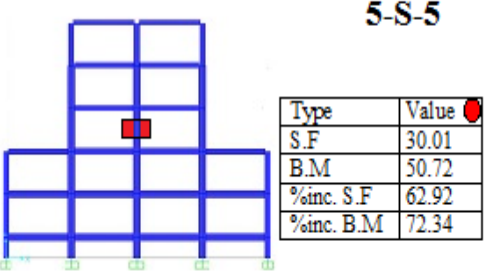

5-S-7

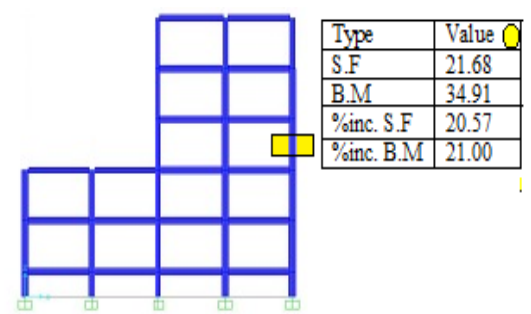

5-S-2

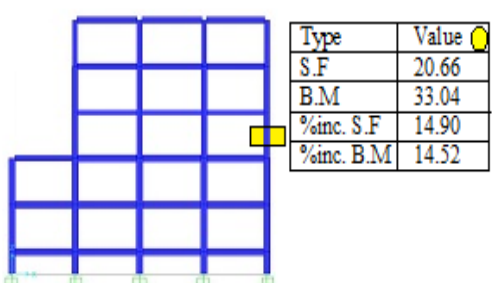

5-S-5

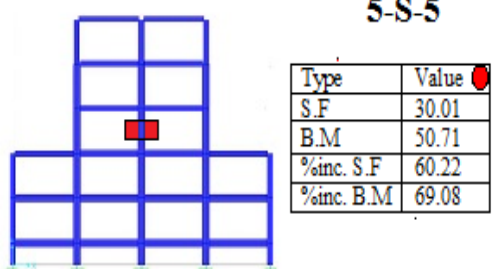

5-S-7

Y Direction

Fig: 5 Variation in shear force and bending moment at different columns obtain from response spectrum analysis of 5 storey regular building to that of setback building. 


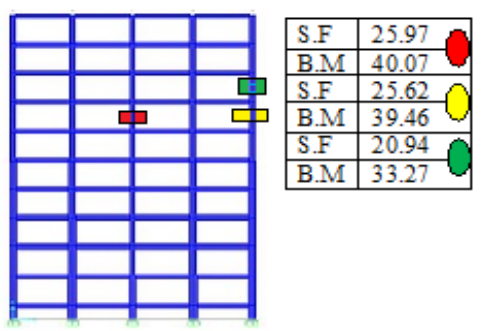

10-R

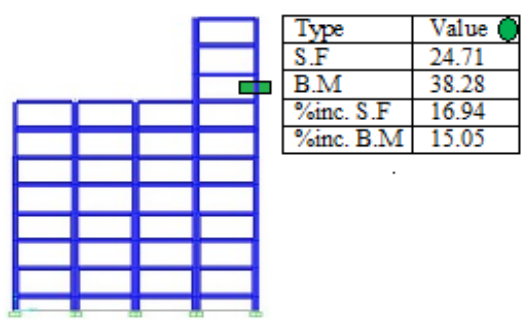

10-S-3

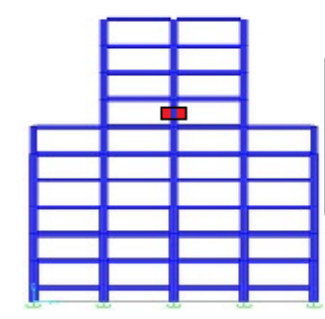

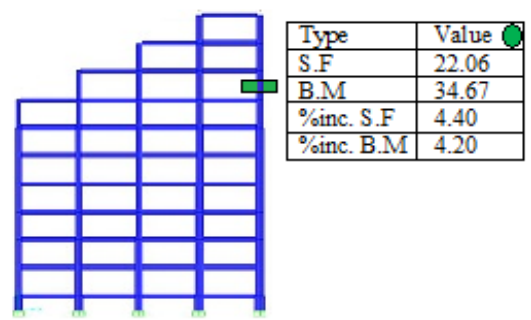

10-S-1

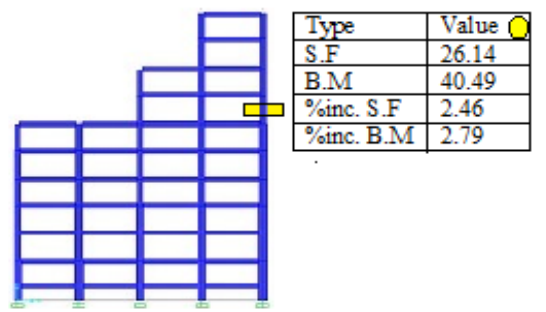

10-S-4

\begin{tabular}{|l|l|}
\hline Type & Value Q \\
\hline S.F & 31.70 \\
\hline B.M & 47.98 \\
\hline \%inc. S.F & 22.06 \\
\hline \%inc. B.M & 19.70 \\
\hline
\end{tabular}

10-S-6

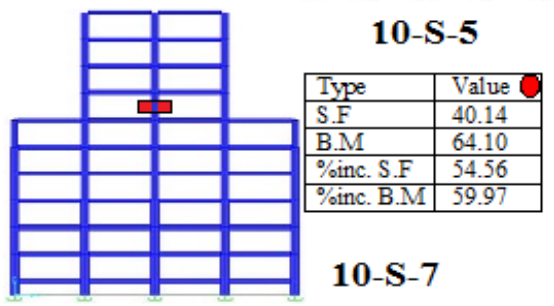

X Direction
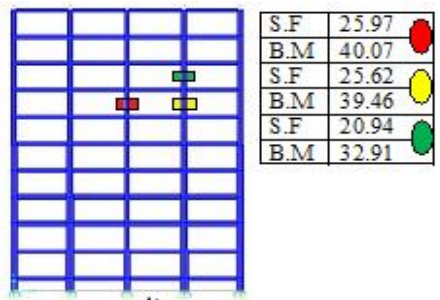

10-R

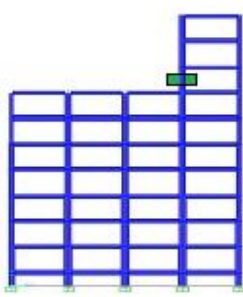

10-S-3
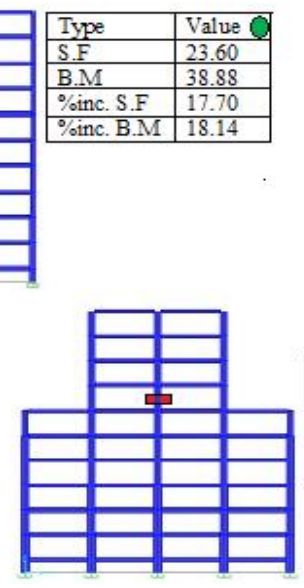

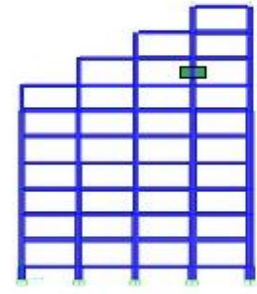

10-S-1

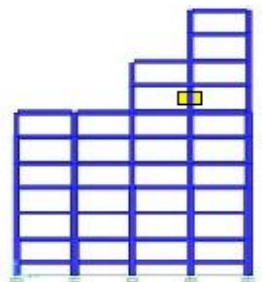

10-S-4
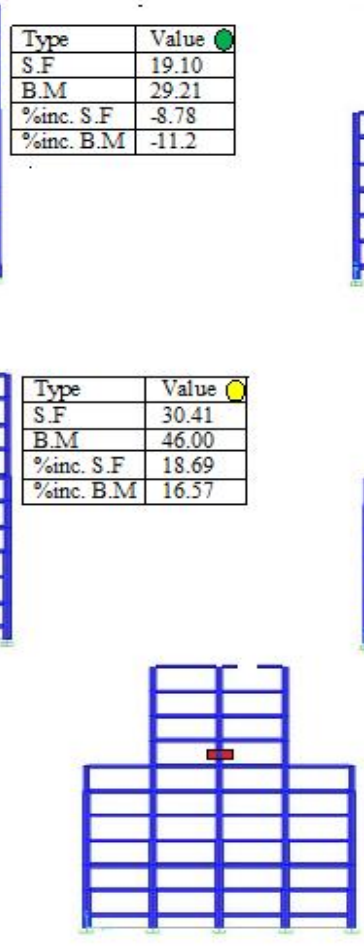

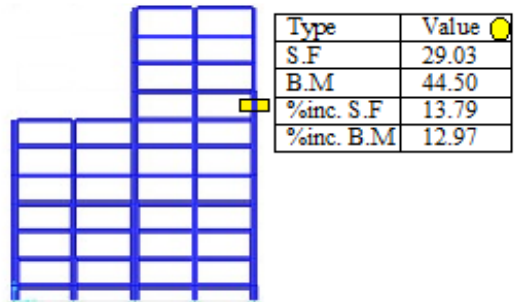

10-S-2

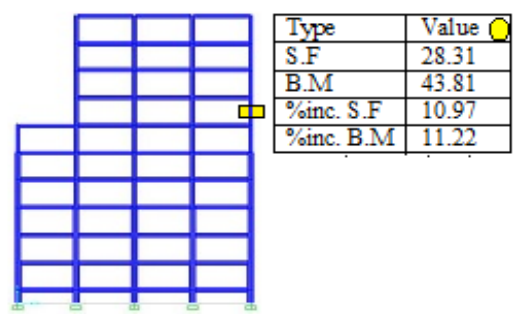

10-S-5 